\title{
Infertilitetsbehandling og kreftrisiko
}

\begin{abstract}
BAKGRUNN En mulig sammenheng mellom hormonstimulering ved infertilitetsbehandling og risiko for mamma-, ovarial-, cervix- og uterinkreft har vært undersøkt i flere epidemiologiske studier. Formålet med denne artikkelen er å gjennomgå den relevante litteraturen og oppsummere funnene derfra.
\end{abstract}

KUNNSKAPSGRUNNLAG Denne oversiktsartikkelen er basert på litteratursøk i databasene MEDLINE, Cochrane og EMBASE.

RESULTATER Ingen studier viste sikker generell sammenheng mellom hormonell ovarial stimulering som forbehandling ved assistert befruktning, og økt risiko for kreftutvikling i mamma, ovarier, uterus eller cervix. I de fleste studier fant man ingen økt risiko. Noen studier viste imidlertid økning i risiko for kreftutvikling hos subgrupper, som for eksempel hos kvinner som har fått gjentatte behandlinger med klomifensitrat.

FORTOLKNING Konklusjonene er, bedømt ut fra de gjenomgåtte studiene, ikke entydige. Det er derfor nødvendig med monitorering av den langsiktige påvirkningen av infertilitetsbehandling på kvinnens helse. Flere gode og større befolkningsstudier med lengre oppfølgingsperioder og bedre justering for medvirkende faktorer er nødvendig.

Befolkningsstudier viser en forekomst av infertilitet på omtrent $9 \%$, og drøyt halvparten av disse parene vil oppsøke helsevesenet for utredning og behandling (1). Assistert befruktning med intrauterin inseminasjon (IUI) eller in vitro-fertilisering (IVF) benyttes ofte i behandling av infertile par. I den vestlige verden er 2,3\% av alle levende fødte barn unnfanget ved hjelp av assistert befruktning (2). I forbindelse med in vitro-fertilisering benyttes vanligvis en kombinasjon av hormoner slik som gonadotropinfrigjørende hormon (GnRH)-agonist eller -antagonist, gonadotropiner og progesteron samt klomifensitrat (CC). Sistnevnte er ofte benyttet som hormonstimulering i startfasen av utredning og behandling og ved intrauterin inseminasjon. Det finnes evidens for at behandling med kvinnelige kjønnshormoner i menopausen er assosiert med økt risiko for flere kreftformer, som for eksempel i bryst og i endometriet (3). Økt cellevekst kan være årsak her. Økt antall eggløsninger, follikkelaspirasjoner, inflammasjon og reparasjonsmekanismer kan spille en rolle ved ovarialkreft (4).

En eventuell sammenheng mellom infertilitet, infertilitetsbehandling med ovarialstimulerende medikamenter og forekomst av kreft, især i bryst, ovarier, uterus eller cervix, har vært gjenstand for mange epidemiologiske studier. Hensikten med denne oversiktsartikkelen er å oppsummere det som er rapportert i litteraturen om mulige sammenhenger mellom infertilitetsbehandling og kreftrisiko.

\section{Kunnskapsgrunnlag}

Artikkelen er basert på litteratursøk i MEDLINE, Cochrane og EMBASE avsluttet 1.9. 2011. Følgende emneord ble benyttet: «fer- tilization in vitro», «intracytoplasmic sperm injection», «assisted reproductive techniques», «ovulation induction», «superovulation», «chorionic gonadotropin», «follicle stimulating hormone», «luteinizing hormone», «progesterone», «chlomiphene», «neoplasms», «ovary», «uterus», «endometrium», «cervix uteri», «myometrium», «breast», «mammary glands», «trophoblastic neoplasms», «choriocarcinoma», «placental site trophoblastic tumor», «hydatiform mole». Søket ble begrenset til «systematic reviews», «observational studies». Totalt 1128 artikler ble funnet. Humane studier publisert på engelsk ble inkludert.

Sammendragene til de identifiserte artiklene ble lest gjennom av AKO og NBO og artikler som omhandlet kreft og forstadier til kreft relatert til follikkelstimulerende og/eller ovulasjonsstimulerende infertilitetsbehandling ble inkludert. Kasuistikker ble ekskludert. Artiklene er gjennomlest av RS, AKO, NBO. Vi inkluderte også enkelte artikler publisert etter at søket ble utført til perioden frem til innsending av manuskriptet.

\section{Risiko for brystkreft}

Ifølge tall fra Kreftregisteret for perioden 2005-09 var kumulativ risiko for brystkreftutvikling hos norske kvinner $8 \%$ (5). I tabell 1 vises data og konklusjoner fra publikasjoner som omhandler risiko for brystkreft etter infertilitetsbehandling. Flere rapporter konkluderer med at det ikke er økt risiko for brystkreft etter infertilitetsbehandling (6-13). I noen studier konkluderes det med en redusert risiko for brystkreft etter behandling for infertilitet $(14,15)$. Det er imidlertid flere studier som rapporterer en

\section{Ritsa Storeng}

ritsa.storeng@rikshospitalet.no

Siri Vangen

Nasjonal kompetansetjeneste for kvinnehelse Avdeling for kvinne- og barnehelse

Kvinne- og barneklinikken

\section{Anne Katerine Omland}

Nan Birgitte Oldereid

Reproduksjonsmedisinsk seksjon

Gynekologisk avdeling

Oslo universitetssykehus, Rikshospitalet

ㄴ.

Engelsk oversettelse på www.tidsskriftet.no

\section{HOVEDBUDSKAP}

Det er ingen klar sammenheng mellom bruk av ovulasjonsstimulerende medikamenter ved assistert befruktning og økt risiko for kreft i mamma, ovarie, cervix eller uterus

Infertilitet i seg selv kan ha sammenheng med økt risiko for enkelte kreftformer

Det er nødvendig med flere gode epidemiologiske studier 
Tabell 1 Studier der man har undersøkt risiko for brystkreft etter infertilitetsbehandling

Førsteforfatter (ref.) $\quad \AA$ A $\quad$ Antall deltakere Hormonbehandling $\quad$ Brystkrefttilfeller Risiko (95\% KI)

\section{Kohortstudier}

\begin{tabular}{|c|c|c|c|c|c|}
\hline Lerner-Geva (11) & 2012 & 2431 & $\mathrm{CC}, \mathrm{CC}+\mathrm{hMG}, \mathrm{hMG}$ & 153 & $S I R=1,2(0,98-1,4)$ \\
\hline Yli-Kuha (13) & 2012 & 9175 & Ikke spesifisert & 50 & $\mathrm{OR}=0,85(0,57-1,30)$ \\
\hline Källeén (14) & 2011 & 24058 & Ikke spesifisert & 112 & $\mathrm{OR}=0,76(0,62-0,94)^{1}$ \\
\hline Calderon-Margalit (6) & 2009 & 15030 & CC, hMG, ukjent & 32 & $\mathrm{HR}=1,42(0,99-2,05)$ \\
\hline Orgeas (20) & 2009 & 1135 & CC, Gon & 54 & $\operatorname{SIR}=1,90(1,08-3,35)^{1}$ \\
\hline Silva (21) & 2009 & 7355 & CC, Gon & 102 & $\operatorname{SIR}=1,26(1,03-1,53)^{1}$ \\
\hline Jensen (17) & 2007 & 54362 & CC, hMG, GnRH-analog, Gon, Prog & 331 & $R R=3,36(1,3-8,6)^{1}$ \\
\hline Lerner-Geva (19) & 2006 & 5788 & $\begin{array}{l}C C \\
h M G, C C+h M G\end{array}$ & 131 & $\begin{array}{l}\mathrm{SIR}=1,4(1,0-1,8) \\
\mathrm{SIR}=1,1(0,9-1,4)\end{array}$ \\
\hline Terry (15) & 2006 & 116671 & CC, hMG & 1357 & $O R=0,60(0,42-0,85)^{1}$ \\
\hline Brinton (16) & 2004 & 12193 & $\begin{array}{l}C C \\
C C \geq 20 \text { års oppfølging } \\
\text { Gon }\end{array}$ & $\begin{array}{r}108 \\
31\end{array}$ & $\begin{array}{l}R R=1,02(0,8-1,3) \\
R R=1,60(1,0-2,5)^{1} \\
R R=1,07(0,7-1,6)\end{array}$ \\
\hline Gauthier (9) & 2004 & 92555 & CC, hMG, hCG & 133 & $\mathrm{RR}=0,95(0,82-1,11)$ \\
\hline Lerner-Geva (10) & 2003 & 1082 & Ikke spesifisert & 5 & $S I R=0,82(0,22-2,10)$ \\
\hline Dor (7) & 2002 & 5026 & CC, hMG, FSH, LH, GnRH-analog & 11 & $S I R=0,69(0,46-1,66)$ \\
\hline Doyle (8) & 2002 & 4188 & CC, hMG, hCG, GnRH-analog & 43 & $\mathrm{RR}=0,95(0,47-1,92)$ \\
\hline Venn (22) & 1999 & 29700 & CC, hMG, GnRH-analog, GH & 87 & $R R=0,96(0,74-1,13)$ \\
\hline Rossing (12) & 1996 & 3837 & $\begin{array}{l}\mathrm{CC} \\
\mathrm{hCG}\end{array}$ & $\begin{array}{r}15 \\
4\end{array}$ & $\begin{array}{l}\mathrm{RR}=0,5(0,2-1,2) \\
\mathrm{RR}=0,5(0,2-1,8)\end{array}$ \\
\hline
\end{tabular}

Pasient-kontroll-studie

\begin{tabular}{l} 
Katz (18) $2008 \quad 7162 \quad \mathrm{CC}, \mathrm{hMG}$, Prog \\
\hline $\mathrm{SIR}=$ standard insidensrate, $\mathrm{OR}=$ oddsratio, $\mathrm{HR}=$ hasardratio, RR = relativ risiko \\
$\mathrm{CC}=$ klomifensitrat, hMG = humant menopausalt gonadotropin, GnRH = gonadotropinfrigjørende hormon, Gon = gonadotropin, Prog = progesteron, \\
$\mathrm{GH}=$ veksthormon \\
1 Signifikant endret risiko
\end{tabular}

øt risiko for brystkreft etter behandling for infertilitet (16-22), spesielt etter gjentatte behandlinger med klomifensitrat (16, 19, $20)$, progesteron (17), og når nullipara kvinner ble behandlet med gonadotropin (17), første året etter IVF-behandling (22) og når kvinnen var 30 år gammel eller eldre ved første IVF-behandling (18).

En metaanalyse publisert i 2010 (23) konkluderte med at det ikke var noen sammenheng mellom hormonstimulering med klomifensitrat, gonadotropiner, gonadotropinfri- gjørende hormon og brystkreft. Forfatterne påpekte imidlertid at de inkluderte studiene $\mathrm{i}$ metaanalysen var heterogene, og at oppfølging etter hormonstimulering var kortvarig.

\section{Risiko for ovarialkreft}

Livstidsrisiko for ovarialkreft er hos kvinner $1,2 \%$ (5). I en rekke studier har man sett på sammenhengen mellom ovarialkreft og infertilitetsbehandling ( $\operatorname{tab} 2$ ). De fleste studier rapporterer ingen okt risiko for ovarialkreft hos kvinner som har fått infertili- tetsbehandling $(6-8,11,13,21,22,24-30)$. Imidlertid rapporterer noen studier om økt risiko for ovarialkreft $(10,14,31)$, økt risiko for borderline tumorer $(30,31)$ og økt risiko etter langvarig bruk av klomifensitrat (32) eller bruk av humant menopausalt gonadotropin (hMG) (33).

\section{Risiko for uterin- og cervixkreft}

Tall fra Kreftregisteret viser en kumulativ risiko for kreft $\mathrm{i}$ uterus og cervix på henholdsvis $2,1 \%$ og $0,9 \%$ (5). I tabellene 3 og 
Tabell 2 Studier der man har undersøkt risiko for ovarialkreft etter infertilitetsbehandling

$\begin{array}{llllll}\text { Førsteforfatter (ref) } \quad \text { Àr } \quad \text { Antall deltakere Hormonbehandling Sykdomstilfeller } & \text { Risiko (95\% KI) }\end{array}$

\section{Kohortstudier}

\begin{tabular}{|c|c|c|c|c|c|}
\hline Lerner-Geva (11) & 2012 & 2431 & $\mathrm{CC}, \mathrm{hMG}, \mathrm{CC}+\mathrm{hMG}$ & Ovarialkreft 18 & $S I R=1,0(0,6-1,6)$ \\
\hline Yli-Kuha (13) & 2012 & 9175 & Ikke spesifisert & $\begin{array}{l}\text { Ovarialkreft } 9 \\
\text { Borderlinetumor } 4\end{array}$ & $\begin{array}{l}\mathrm{OR}=1,68(0,31-9,27) \\
\mathrm{OR}=2,57(0,69-9,63)\end{array}$ \\
\hline Van Leeuwen (30) & 2011 & 25152 & $\begin{array}{l}\text { CC, hMG, FSH, hCG, } \\
\text { GnRH, Prog }\end{array}$ & $\begin{array}{l}\text { Ovarialkreft } 30 \\
\text { Borderlinetumor } 31\end{array}$ & $\begin{array}{l}\mathrm{SIR}=1,35(0,91-1,92) \\
\mathrm{SIR}=1,93(1,31-2,73)^{1}\end{array}$ \\
\hline Källén (14) & 2011 & 24058 & Ikke spesifisert & Ovarialkreft 26 & $\mathrm{OR}=2,09(1,39-3,12)^{1}$ \\
\hline Calderon-Margalit (6) & 2009 & 15030 & CC, hMG, ukjent & Ovarialkreft 1 & $H R=0,61(0,08-4,42)$ \\
\hline Jensen (26) & 2009 & 54362 & $\begin{array}{l}\text { hMG, FSH } \\
\text { CC } \\
\text { hCG } \\
\text { GnRH-analog }\end{array}$ & $\begin{array}{l}\text { Ovarialkreft } 26 \\
\text { Ovarialkreft } 58 \\
\text { Ovarialkreft } 49 \\
\text { Ovarialkreft } 15\end{array}$ & $\begin{array}{l}R R=0,83(0,5-1,37) \\
R R=1,14(0,79-1,64) \\
R R=0,89(0,62-1,29) \\
R R=0,80(0,42-1,51)\end{array}$ \\
\hline Sanner (31) & 2009 & 2768 & $\begin{array}{l}\text { Gon } \\
\text { CC, Gon }\end{array}$ & $\begin{array}{l}\text { Ovarialkreft } 9 \\
\text { Borderlinetumor } 7\end{array}$ & $\begin{array}{l}S I R=5,89(1,91-13,75)^{1} \\
S I R=3,61(1,45-7,44)^{1}\end{array}$ \\
\hline Silva (21) & 2009 & 7355 & CC, Gon & Ovarialkreft 12 & $S I R=1,10(0,57-1,93)$ \\
\hline Brinton (24) & 2004 & 12193 & CC, Gon & $\begin{array}{l}\text { Ovarialkreft } 15 \\
\text { Borderlinetumor } 5\end{array}$ & $\begin{array}{l}R R=0,82(0,4-1,5) \\
R R=1,09(0,4-2,8)\end{array}$ \\
\hline Lerner-Geva (10) & 2003 & 1082 & Ikke spesifisert & Ovarialkreft 3 & $\operatorname{SIR}=5,0(1,02-14,6)^{1}$ \\
\hline Dor (7) & 2002 & 5026 & CC, hMG, FSH, LH & Ovarialkreft 1 & $\mathrm{SIR}=0,57(0,01-3,20)$ \\
\hline Doyle (8) & 2002 & 4188 & $\begin{array}{l}\text { CC, hMG, hCG, } \\
\text { GnRH-analog }\end{array}$ & Ovarialkreft 4 & $R R=0,59(0,12-3,00)$ \\
\hline Venn (22) & 1999 & 29700 & $\begin{array}{l}\text { CC, hMG, GnRH-analog, } \\
\text { GH }\end{array}$ & Ovarialkreft 7 & $S I R=0,88(0,42-1,84)$ \\
\hline Rossing (32) & 1994 & 3837 & $\begin{array}{l}\text { CC } 1-11 \text { sykler } \\
\text { CC } \geq 12 \text { sykler } \\
\text { hCG }\end{array}$ & $\begin{array}{l}\text { Ovarialkreft/borderlinetumor } 3 \\
\text { Ovarialkreft/borderlinetumor } 5 \\
\text { Ovarialkreft/borderlinetumor } 3\end{array}$ & $\begin{array}{l}\mathrm{RR}=0,8(0,1-5,7) \\
\mathrm{RR}=11,1(1,5-82,3)^{1} \\
\mathrm{RR}=1(0,2-4,3)\end{array}$ \\
\hline
\end{tabular}

\section{Pasient-kontroll-studier}

\begin{tabular}{|c|c|c|c|c|c|}
\hline Cusido (25) & 2007 & 299 & CC, Gon & Ovarialkreft 42 & Ikke signifikant \\
\hline Rossing (28) & 2004 & 2015 & $\mathrm{CC}, \mathrm{hMG}, \mathrm{FSH}$ & Ovarialkreft 378 & $\mathrm{OR}=1,0(0,4-3,0)$ \\
\hline Mosgaard (27) & 1998 & 1952 & CC, hCG, hMG & Ovarialkreft 231 & $\begin{array}{l}\mathrm{OR}=1,5(0,51-4,39) \\
\text { nullipara } \\
\mathrm{OR}=1,46(0,56-3,81) \\
\text { multipara }\end{array}$ \\
\hline Shushan (33) & 1996 & 608 & CC, hMG & Ovarialkreft 200 & $\mathrm{OR}=9,38(1,66-52,08)^{1}$ \\
\hline Franceschi (29) & 1994 & 1534 & CC, Gon & Ovarialkreft 195 & $\mathrm{OR}=0,7(0,2-3,3)$ \\
\hline
\end{tabular}

$\mathrm{SIR}=$ standard insidensrate, $\mathrm{OR}=$ oddsratio, $\mathrm{HR}$ = hasardratio, $\mathrm{RR}=$ relativ risiko

$\mathrm{CC}=$ klomifensitrat, $\mathrm{hMG}=$ humant menopausalt gonadotropin, $\mathrm{GnRH}=$ gonadotropinfrigjørende hormon, Gon = gonadotropin, Prog = progesteron, $\mathrm{GH}=$ veksthormon, $\mathrm{FSH}=$ follikkelstimulerende hormon, $\mathrm{hCG}=$ humant choriogonadotropin, $\mathrm{LH}$ = luteiniserende hormon

1 Signifikant endret risiko

4 vises data og konklusjoner fra publikasjoner som omhandler risiko for uterin- og cervixkreft etter infertilitetsbehandling. I seks studier $(6,11,21,22,34,35)$ ble det rapportert signifikant økt risiko for uterinkreft. Økt risiko var knyttet til bruk av klomifensitrat $(6,21,34)$, forbigående økt risiko første året etter behandlingen (22) og lang (30 års) oppfølgingsperiode (11). Ingen $ø \mathrm{kt}$ risiko for uterinkreft som følge av infertilitetsbehand- ling var konklusjonen i flere andre artikler $(7,8,13,14,35)$. Källén og medarbeidere og Yli-Kuha og medarbeidere fant ved gjennomgang av henholdsvis 24058 og 9175 kvinner som hadde gjennomgått IVF-behandling, en lavere forekomst av cervixkreft enn hos andre kvinner $(13,14)$. Andre rapporter $(6-8,10,36)$ konkluderte med at det ikke var økt risiko for cervixkreft som følge av infertilitetsbehandling.

\section{Diskusjon}

Denne litteraturgjennomgangen har ikke vist noen klar sammenheng mellom hormonell infertilitetsbehandling som benyttes ved assistert befruktning og økt risiko for kreft $\mathrm{i}$ mamma, ovarier, uterus eller cervix. Fordi mange kvinner som har gjennomgått hormonell infertilitetsbehandling fortsatt er relativt unge, vil det gå flere år til de har nådd alderen med høyest kreftinsidens. Et generelt 
Tabell 3 Kohortstudier der man har undersøkt risiko for uterinkreft etter infertilitetsbehandling

\begin{tabular}{|c|c|c|c|c|c|}
\hline Førsteforfatter (ref) & $\AA ̊$ & Antall deltakere & Hormonbehandling & Uterinkrefttilfeller & Risiko (95\% KI) \\
\hline Lerner-Geva (11) & 2012 & 2431 & $C C+h M G, C C, h M G$ & 30 & $\mathrm{SIR}=1,7(1,1-2,4)^{1}$ \\
\hline Yli-Kuha (13) & 2012 & 9175 & Ikke spesifisert & 4 & $O R=2,0(0,37-10,9)$ \\
\hline Källén (14) & 2011 & 24058 & Ikke spesifisert & 6 & Ikke oppgitt \\
\hline Calderon-Margalit (6) & 2009 & 15030 & CC, hMG, ukjent & 5 & $\mathrm{HR}=3,32(1,31-8,42)^{1}$ \\
\hline Silva (21) & 2009 & 7355 & $\begin{array}{l}\mathrm{CC}+\mathrm{Gon} \\
\mathrm{CC} \\
\text { Gon }\end{array}$ & 18 & $\begin{array}{l}S I R=2,51(1,01-5,16)^{1} \\
S I R=2,23(1,07-4,11)^{1} \\
S I R=1,93(0,05-10,75)\end{array}$ \\
\hline Jensen (35) & 2009 & 54362 & $\begin{array}{l}\text { CC, hCG } \\
\text { Gon } \\
\text { GnRH-analog }\end{array}$ & 84 & $\begin{array}{l}R R=1,36(0,83-2,23) \\
R R=2,21(1,08-4,50)^{1} \\
R R=1,09(0,47-2,52)\end{array}$ \\
\hline Althuis (34) & 2005 & 8431 & $\mathrm{CC}$ & 19 & $\mathrm{SIR}=2,14(1,3-3,3)^{1}$ \\
\hline Dor (7) & 2002 & 5026 & CC, hMG, FSH, LH, GnRH-analog & 2 & $\operatorname{SIR}=2,25(0,25-8,11)$ \\
\hline Doyle (8) & 2002 & 4188 & CC, hMG, hCG, GnRH-analog & 3 & $\mathrm{RR}=0,72(0,06-8,62)$ \\
\hline Venn (22) & 1999 & 29700 & $\mathrm{CC}, \mathrm{hMG}, \mathrm{GnRH}-$ analog, $\mathrm{GH}$ & 5 & $\begin{array}{l}\mathrm{SIR}=1,09(0,45-2,61) \\
\mathrm{SIR}=4,96(1,24-19,8)(1 \mathrm{ar} r \\
\text { etter behandling })^{1}\end{array}$ \\
\hline
\end{tabular}

$\mathrm{SIR}=$ standard insidensrate, $\mathrm{OR}=$ oddsratio, $\mathrm{HR}=$ hasardratio, $\mathrm{RR}=$ relativ risiko

$\mathrm{CC}=$ klomifensitrat, $\mathrm{hMG}=$ humant menopausalt gonadotropin, $\mathrm{GnRH}=$ gonadotropinfrigjørende hormon, Gon = Gonadotropin, Prog = Progesteron,

$\mathrm{GH}=$ veksthormon, $\mathrm{FSH}=$ follikkelstimulerende hormon, $\mathrm{LH}=$ luteiniserende hormon

1 Signifikant endret risiko

Tabell 4 Kohortstudier der man har undersøkt risiko for cervixkreft etter infertilitetsbehandling

\begin{tabular}{|c|c|c|c|c|c|}
\hline Førsteforfatter (ref) & $\AA ̊ \AA r$ & Antall deltakere & Hormonbehandling & Cervixkrefttilfeller & Risiko (95 \% KI) \\
\hline Yli-Kuha (13) & 2012 & 9175 & Ikke spesifisert & 34 & $\mathrm{OR}=0,51(0,30-0,85)^{1}$ \\
\hline Källén (14) & 2011 & 24058 & Ikke spesifisert & 164 & $\mathrm{OR}=0,61(0,52-0,71)^{1}$ \\
\hline Calderon-Margalit (6) & 2009 & 15030 & CC, hMG, ukjent & 2 & $H R=1,68(0,40-7,04)$ \\
\hline Althuis (36) & 2005 & 8422 & $\begin{array}{l}\text { CC } \\
\text { Gon }\end{array}$ & $\begin{array}{l}7 \\
2\end{array}$ & $\begin{array}{l}\mathrm{RR}=1,61(0,5-4,7) \\
\mathrm{RR}=1,39(0,3-6,4)\end{array}$ \\
\hline Lerner-Geva (10) & 2003 & 1082 & Ikke spesifisert & 3 & $\operatorname{SIR}=4,61(0,93-13,49)$ \\
\hline Dor (7) & 2002 & 5026 & CC, hMG, FSH, LH, GnRH-analog & 1 & $\mathrm{SIR}=0,58(0,01-3,22)$ \\
\hline Doyle (8) & 2002 & 4188 & CC, hMG, hCG, GnRH-analog & 3 & Ikke beregnelig \\
\hline
\end{tabular}

$\mathrm{SIR}=$ standard insidensrate, $\mathrm{OR}=$ oddsratio, $\mathrm{HR}=$ hasardratio, $\mathrm{RR}=$ relativ risiko

$\mathrm{CC}=$ klomifensitrat, $\mathrm{hMG}=$ humant menopausalt gonadotropin, $\mathrm{GnRH}=$ gonadotropinfrigjørende hormon, Gon = gonadotropin, $\mathrm{LH}=$ luteiniserende hormon, FSH = follikkelstimulerende hormon

1 Signifikant endret risiko

trekk ved de inkluderte studiene var lavt antall krefttilfeller. Flere studier viste en tendens til økt risiko ved infertilitetsbehandling. Til tross for store kohorter var antallet kvinner som utviklet kreft, for lavt til å oppnå signifikante resultater. Dette viser behovet for større studier og metaanalyser som kan gi mer presise resultater. Det er også viktig å poengtere at epidemiologiske undersøkelser ikke kan si noe sikkert om årsaken til kreftutvikling. Andre faktorer som er assosiert med både infertilitet og kreft, slik som overvekt $(37,38)$, kan også spille en rolle. Infertilitet generelt, samt årsaker til infertilitet slik som endometriose (39, 40), ovulasjonsforstyrrelser, polycystisk ovarie-syndrom $(37,41)$ og tubarfaktor $(42,43)$ kan påvirke risikoen for utvikling av kreft i mamma, ovarier eller uterus.

Hormonbehandlingen eksponerer kvin- nene for suprafysiologiske konsentrasjoner av eksogene hormoner med følgelig økning i østrogen- og progesteronkonsentrasjoner som muligens kan bidra til økt risiko for brystkreft. De fleste studier vi gjennomgikk $\mathrm{i}$ tabell 1 viste at det ikke forelå økt risiko for brystkreft assosiert med infertilitetsbehandling. Men en av studiene, en pasient-kontroll-studie (18), konkluderte med at kvinner som gjennomgikk IVF-behandlingen etter 
fylte 30 år, fikk påvist brystkreft tidligere (gjennomsnittsalder 43,9 år) enn kvinner i den generelle befolkningen som i denne rapporten var i gjennomsnitt 60 år ved diagnosetidspunkt. En studie antydet at IVFbehandlingen beskytter kvinnene mot brystkreft (14). Noen av de gjennomgåtte studiene viser imidlertid en økt risiko for utvikling av mammacancer spesielt etter behandling med klomifensitrat og 20 års oppfølging (16), gonadotropin (21) og progesteron (17). Men igjen er resultatene ikke overbevisende og evidensen ikke klar.

Behandling med klomifensitrat og gonadotropiner i forbindelse med assistert befruktning stimulerer follikkelmodningen og induserer ovulasjon. Ovulasjonen i seg selv kan inngå i mekanismer som knyttes til ovarialkreft-etiologi $(44,45)$. Hypotesen om uopphørlig ovulasjon (incessant ovulation) (45) postulerer at hyppige ovulasjoner som fører til skade og reparasjon av ovariets overflateepitel, øker sannsynligheten for DNA-mutasjoner og kan predisponere for malign transformasjon (4). Dette kan forklare hvorfor flergangsfødende kvinner har $30-70 \%$ lavere risiko for ovarialkreft enn kvinner som ikke har født barn (46-48).

Källén og medarbeidere (14) rapporterte i sin studie om kreftrisiko hos kvinner som fødte barn etter IVF-behandling. Kontrollgruppe var kvinner som fødte barn uten IVFbehandling. De fant en økt kreftrisiko, spesielt for ovarialkreft, hos IVF-kvinnene både før og etter graviditet/fødsel. Kreftrisikoen var imidlertid redusert etter fødsel. Dette kan muligens forklares med at ovarialpatologiske forhold kan være årsaken til både infertilitet og økt risiko for ovarialkreft. Dette er også konklusjonen i studiene til Jensen og medarbeidere etter undersøkelse av en kohort bestående av 54362 kvinner $(26,49)$. En studie fra Nederland publisert i 2011 (30) og en studie fra Sverige publisert i 2009 (31) evaluerte risikoen for borderline-ovarialtumor og invasiv ovarialkreft, og rapporterte en mulig økning i risiko for borderlinetumor i ovarier og muligens økt risiko for invasiv ovarialkreft etter behandling med gonadotropin (31). Det er viktig å understreke at bordeline ovarialtumor i utgangspunktet er en benign sykdom med et lavt malignitetspotensial. Vi har likevel valgt å ta dette funnet med i tabellen fordi det har betydning for kvinnen det gjelder. Konvensjonell behandling for denne tilstanden er bilateral ooforektomi og hormonsubstitusjon.

Til tross for store kohorter av kvinner som mottar in vitro-fertilisering, er antallet kvinner som utvikler kreft liten, og studiene er basert på små tall. Det er derfor nødvendig med en fortsatt monitorering av den langsiktige påvirkningen av hormonstimulering ved infertilitetsbehandling med henblikk på risiko for utvikling av invasiv ovarialkreft og borderlinetumorer.

Etter 30 års oppfølging fant Lerner-Geva og medarbeidere en signifikant økning i insi- densen av endometriekreft hos kvinner som ble behandlet med klomifensitrat og hMG (11). I en studie ble det beskrevet en forbigående økt risiko for uterinkreft det første året etter gjennomgått ovulasjonsinduksjon, spesielt hos kvinner med uforklarlig infertilitet (22). Flere studier konkluderte med at infertilitetsbehandling med klomifensitrat, $\mathrm{hMG}$, gonadotropin og gonadotropinfrigjørendehormon-analoger kan føre til økt risiko for uterinkreft $(6,11,21,34,35)$, mens andre ikke fant noen økt risiko $(7,8,13,14)$. Det var ikke forventet $ø \mathrm{kt}$ risiko for cervixkreft etter infertilitetsbehandling med eksogene hormoner. Det var også konklusjonen i alle studiene som ble gjennomgått (tab 4). Imidlertid ble det rapportert en redusert risiko for cervixkreft $i$ to studier $(13,14)$. En mulig forklaring kan være at kvinner som gjennomgår fertilitetsbehandling oftere undersøkes gynekologisk og derved behandles tidligere for celleatypier i cervix (13).

\section{Konklusjon}

Behandling med follikkelstimulerende medikamenter ser ikke ut til å øke risikoen for kreftutvikling generelt, men infertilitet i seg selv kan være en risikofaktor for kreftutvikling. Dette gjør tolking av epidemiologiske studier av kreftrisiko etter infertilitetsbehandling krevende. Det synes som enkelte subgrupper av infertile kvinner kan være mer utsatt for en økt kreftrisiko ved behandling. Kreftrisiko avhenger også av om kvinnen har oppnådd graviditet og født barn som resultat av behandlingen. Det kan være grunn til å vise forsiktighet med langvarig bruk av klomifensitrat, spesielt dersom det ikke foreligger anovulasjon.

Klarlegging av prediktive faktorer er viktig for å identifisere hvilke kvinner som eventuelt bør tilbys ekstra oppfølging etter gjennomført infertilitetsbehandling. Vår gjenomgang viser at det fortsatt er nødvendig med monitorering av den langsiktige påvirkningen av hormonbehandlingen på kvinnens helse.

Vi takker Malene Wøhlk Gundersen, Avdeling for bibliotek og publikasjoner, Helsedirektoratet, og Anne Karin Lindahl, Nasjonalt kunnskapssentere for helsetjenesten for hjelp med litteratursøk Pernille Frese ved Nasjonal kompetansetjeneste for kvinnehelse takkes for verdifullt bidrag.

\section{Ritsa Storeng (f. 1948)}

er dr.philos. og seniorforsker innen feltet reproduksjonsmedisin.

Forfatter har fylt ut ICMJE-skjemaet og oppgir ingen interessekonflikter.

\section{Siri Vangen (f. 1954)}

er overlege, dr.med., spesialist i fødselshjelp og kvinnesykdommer. Hun arbeider som sek sjonsleder ved Nasjonal kompetansetjeneste for kvinnehelse.

Forfatter har fylt ut ICMJE-skjemaet og oppgir ingen interessekonflikter.

\section{Anne Katerine Omland (f. 1951)}

er overlege, ph.d., spesialist i fødselshjelp og kvinnesykdommer, med spesialkompetanse i assistert befruktning.

Forfatter har fylt ut ICMJE-skjemaet og oppgir ingen interessekonflikter.

\section{Nan B. Oldereid (f. 1959)}

er overlege, dr.med., spesialist i fødselshjelp og kvinnesykdommer, med spesialkompetanse i assistert befruktning. Hun har vært tilknyttet Nasjonal kompetansetjeneste for kvinnehelse. Forfatter har fylt ut ICMJE-skjemaet og oppgir ingen interessekonflikter.

\section{Litteratur}

1. Boivin J, Bunting L, Collins JA et al. International estimates of infertility prevalence and treatment seeking: potential need and demand for infertility medical care. Hum Reprod 2007: 22: 1506-12.

2. Wright VC, Chang J, Jeng $G$ et al. Assisted reproductive technology surveillance-United States, 2005. MMWR Surveill Summ 2008; 57: 1-23.

3. U.S.Department of Health and Human Services, National Institutes of Health. FactSheet; Menopausal hormone therapy and cancer. www.cancer.gov/cancertopics/factsheet/Risk/ menopausal-hormones (10.10.2012).

4. Farley J, Ozbun LL, Birrer MJ. Genomic analysis of epithelial ovarian cancer. Cell Res 2008; 18 : 538-48.

5. Haldorsen T, red. Cancer in Norway 2009. Specia issue: Cancer screening in Norway. Oslo: Kreftregisteret, 2011.

6. Calderon-Margalit R, Friedlander $Y$, Yanetz $\mathrm{R}$ et al. Cancer risk after exposure to treatments for ovulation induction. Am J Epidemiol 2009; 169: 365-75.

7. Dor J, Lerner-Geva L, Rabinovici J et al. Cancer incidence in a cohort of infertile women who underwent in vitro fertilization. Fertil Steril 2002; 77: $324-7$

8. Doyle P Maconochie N, Beral V et al. Cancer incidence following treatment for infertility at a clinic in the UK. Hum Reprod 2002; 17: 2209-13.

9. Gauthier E, Paoletti X, Clavel-Chapelon F; E3N group. Breast cancer risk associated with being treated for infertility: results from the French E3N cohort study. Hum Reprod 2004; 19: 2216-21.

10. Lerner-Geva L, Geva E, Lessing JB et al. The possible association between in vitro fertilization treatments and cancer development. Int J Gynecol Cancer 2003: 13: 23-7.

11. Liat LG, Jaron R, Liraz $O$ et al. Are infertility treatments a potential risk factor for cancer development? Perspective of 30 years of follow-up. Gynecol Endocrinol 2012; 28: 809-14

12. Rossing MA, Daling JR, Weiss NS et al. Risk of breast cancer in a cohort of infertile women. Gynecol Oncol 1996; 60: 3-7.

13. Yli-Kuha AN, Gissler M, Klemetti R et al. Cancer morbidity in a cohort of 9175 Finnish women treated for infertility. Hum Reprod 2012; 27: 1149-55.

14. Källén B, Finnström O, Lindam A et al. Malignancies among women who gave birth after in vitro fertilization. Hum Reprod 2011: 26: 253-8.

15. Terry KL, Willett WC, Rich-Edwards JW et al. A prospective study of infertility due to ovulatory disorders, ovulation induction, and incidence of breast cancer. Arch Intern Med 2006; 166: 2484-9.

16. Brinton LA, Scoccia B, Moghissi KS et al. Breast cancer risk associated with ovulation-stimulating drugs. Hum Reprod 2004; 19: 2005-13.

17. Jensen A, Sharif H, Svare El et al. Risk of breast cancer after exposure to fertility drugs: results from a large Danish cohort study Cancer Epidemiol Biomarkers Prev 2007; 16: 1400-7.

18. Katz D, Paltiel O, Peretz T et al. Beginning IVF treatments after age 30 increases the risk of breast cancer: results of a case-control study. Breast J 2008; 14: 517-22. 
19. Lerner-Geva L, Keinan-Boker L, Blumstein T et al. Infertility, ovulation induction treatments and the incidence of breast cancer-a historical prospective cohort of Israeli women. Breast Cancer Res Treat 2006: 100: 201-12.

20. Orgéas CC, Sanner K, Hall P et al. Breast cancer incidence after hormonal infertility treatment in Sweden: a cohort study. Am J Obstet Gynecol 2009: 200: 72.e1-7.

21. dos Santos Silva I, Wark PA, McCormack VA et al. Ovulation-stimulation drugs and cancer risks: a long-term follow-up of a British cohort. $\mathrm{Br}$. Cancer 2009; 100: 1824-31.

22. Venn A, Watson L, Bruinsma F et al. Risk of cancer after use of fertility drugs with in-vitro fertilisation. Lancet 1999; 354: 1586-90.

23. Zreik TG, Mazloom A, Chen Y et al. Fertility drugs and the risk of breast cancer: a meta-analysis and review. Breast Cancer Res Treat 2010; 124: 13-26.

24. Brinton LA, Lamb EJ, Moghissi KS et al. Ovarian cancer risk associated with varying causes of infertility. Fertil Steril 2004; 82: 405-14.

25. Cusidó M, Fábregas R, Pere BS et al. Ovulation induction treatment and risk of borderline ovarian tumors. Gynecol Endocrinol 2007; 23: 373-6.

26. Jensen A, Sharif H, Frederiksen K et al. Use of fertility drugs and risk of ovarian cancer: Danish Population Based Cohort Study. BMJ 2009; 338: b249.

27. Mosgaard BJ, Lidegaard O, Kjaer SK et al. Ovarian stimulation and borderline ovarian tumors: a case-control study. Fertil Steril 1998; 70: 1049-55.

28. Rossing MA, Tang MT, Flagg EW et al. A casecontrol study of ovarian cancer in relation to infertility and the use of ovulation-inducing drugs. Am J Epidemiol 2004; 160: 1070-8

29. Franceschi S, La Vecchia C, Negri E et al. Fertility drugs and risk of epithelial ovarian cancer in Italy. Hum Reprod 1994; 9: 1673-5.
30. van Leeuwen FE, Klip H, Mooij TM et al. Risk of borderline and invasive ovarian tumours after ovarian stimulation for in vitro fertilization in a large Dutch cohort. Hum Reprod 2011; 26: $3456-65$.

31. Sanner K, Conner P, Bergfeldt K et al. Ovarian epithelial neoplasia after hormonal infertility treatment: long-term follow-up of a historical cohort in Sweden. Fertil Steril 2009; 91: 1152-8.

32. Rossing MA, Daling JR, Weiss NS et al. Ovarian tumors in a cohort of infertile women. $\mathrm{N}$ Engl J Med 1994; 331: 771-6.

33. Shushan A, Paltiel O, Iscovich J et al. Human menopausal gonadotropin and the risk of epithelial ovarian cancer. Fertil Steril 1996; 65: 13-8.

34. Althuis MD, Moghissi KS, Westhoff CL et al. Uterine cancer after use of clomiphene citrate to induce ovulation. Am J Epidemiol 2005: 161 : 607-15.

35. Jensen A, Sharif H, Kjaer SK. Use of fertility drugs and risk of uterine cancer: results from a large Danish population-based cohort study. Am J Epidemiol 2009: 170: 1408-14

36. Althuis MD, Scoccia B, Lamb EJ et al. Melanoma, thyroid, cervical, and colon cancer risk after use of fertility drugs. Am J Obstet Gynecol 2005; 193: $668-74$

37. Health and fertility in World Health Organization group 2 anovulatory women. Hum Reprod Update 2012; e-publisert 19.5.2012.

38. Tretli S, Magnus K. Height and weight in relation to uterine corpus cancer morbidity and mortality. A follow-up study of 570,000 women in Norway. Int J Cancer 1990; 46: 165-72

39. Pearce CL, Templeman C, Rossing MA et al. Association between endometriosis and risk of histological subtypes of ovarian cancer: a pooled analysis of case-control studies. Lancet Oncol 2012; 13: $385-94$.
40. Giudice LC, Kao LC. Endometriosis. Lancet 2004: 364: 1789-99.

41. Balen A. Polycystic ovary syndrome and cancer. Hum Reprod Update 2001; 7: 522-5.

42. Levanon K, Crum C, Drapkin R. New insights into the pathogenesis of serous ovarian cancer and its clinical impact. J Clin Oncol 2008; 26: 5284-93.

43. Manchanda R, Drapkin R, Jacobs I et al. The role of peritoneal cytology at risk-reducing salpingooophorectomy (RRSO) in women at increased risk of familial ovarian/tubal cancer. Gynecol Oncol 2012; 124: 185-91.

44. Brinton LA, Moghissi KS, Scoccia B et al. Ovulation induction and cancer risk. Fertil Steril 2005; 83: 261-74.

45. Fathalla MF. Incessant ovulation - a factor in ovarian neoplasia? Lancet 1971; 2: 163.

46. Adami HO, Hsieh CC, Lambe M et al. Parity, age at first childbirth, and risk of ovarian cancer. Lancet 1994; 344: 1250-4.

47. Hankinson SE, Colditz GA, Hunter DJ et al. A prospective study of reproductive factors and risk of epithelial ovarian cancer. Cancer 1995; 76: 284-90.

48. Mosgaard BJ, Lidegaard O, Kjaer SK et al. Infertility, fertility drugs, and invasive ovarian cancer: a case-control study. Fertil Steril 1997; 67: 1005-12.

49. Jensen A, Sharif H, Olsen JH et al. Risk of breast cancer and gynecologic cancers in a large popula tion of nearly 50,000 infertile Danish women. Am J Epidemiol 2008; 168: 49-57.

Mottatt 26.3. 2012, første revisjon innsendt 5.7. 2012, godkjent 2.10.2012. Medisinsk redaktør Kristin Viste. 